\title{
Adenomioepitelioma de la Mama: Reporte de un Caso
}

\author{
Adenomyoepithelioma of the Breast: A Case Report.
}

Oscar Tapia E.

TAPIA, E. O. Adenomioepitelioma de la mama: Reporte de un caso. Int. J. Morphol., 29(3):891-894, 2011.

RESUMEN: El adenomioepitelioma es un infrecuente tumor de la mama, conformado por una proliferación bifásica de células epiteliales y mioepiteliales. Presentamos las características clínicas y morfológicas de un caso de adenomioepitelioma benigno diagnosticado en una paciente de 34 años en la Unidad de Anatomía Patológica del Hospital Hernán Henríquez Aravena de Temuco.

PALABRAS CLAVE: Neoplasia de mama; Adenomioepitelioma; Células mioepiteliales.

\section{INTRODUCCIÓN}

El adenomioepitelioma es un infrecuente tumor de la mama, conformado por una proliferación bifásica de células epiteliales y mioepiteliales (Chu et al., 2006; Lee $e t$ al., 2010; Rosen, 1987). La mayoría de estos tumores presentan un comportamiento benigno, sin embargo, en raras ocasiones presenta degeneración maligna (Catena et al., 2008).

Presentamos las características clínicas y morfológicas de un caso de adenomioepitelioma benigno diagnosticado en una paciente de 34 años en la Unidad de Anatomía Patológica del Hospital Hernán Henríquez Aravena de Temuco, Chile.

\section{REPORTE DE CASO}

Mujer de 34 años, menarquia a los dieciseis años, un parto a los diecinueve años, tiempo total de lactancia aproximado de doce meses, usuaria de dispositivo intrauterino y antecedente de abuela materna con cáncer de mama. Derivada desde centro de atención primaria por pesquiza de nódulo en cuadrante supero lateral de mama derecha, de aproximadamente $2 \times 3 \mathrm{~cm}$, de bordes polilobulados y móvil. La mamografía bilateral demostró en la mama derecha imagen nodular polilobulada con calcificaciones en su interior, de 2,5 cm de diámetro mayor. En la ecotomografía se aprecian 3 formaciones nodulares hipoecogénicas de aspecto sólido, contornos lobulados, y calcificaciones en su espesor de 1,4,1,8 y $2 \mathrm{~cm}$; sin aumento de la vascularización al modo Doppler color, sugerentes de corresponder a fibroadenomas.

Se efectuó tumorectomía, examinándose 3 fragmentos de tejido glandular mamario de 1,5,2,5 y $4 \mathrm{~cm}$ que en la superficie de corte presentan múltiples áreas nodulares, lobuladas, bien delimitadas y consistencia aumentada. Al examen microscópico, se reconoce proliferación neoplásica bien delimitada, constituida por estructuras tubulares conformadas por células epiteliales ductales normotípicas y células mioepiteliales dispuestas basalmente, de citoplasma vacuolado y claro; con presencia de abundantes calcificaciones pequeñas-medianas intraluminales (Fig. 1A-C). Se reconoce compromiso de uno de los bordes quirúrgicos en uno de los fragmentos examinados. El estudio inmunohistoquímico para células mioepiteliales demostró positividad para actina músculo liso (SMA) (Fig. 1D-E). No se encontró necrosis, atipía citológica ni mitosis.

La paciente no presentó complicaciones postoperatorias. Actualmente se encuentra en controles, demostrándose luego de transcurridos 15 meses aumento de volumen en la zona operatoria correspondiendo en el contexto de la paciente (resección incompleta) a una recurrencia de la lesión.

\footnotetext{
* Departamento de Anatomía Patológica. Facultad de Medicina. Universidad de La Frontera, Temuco, Chile.

** BIOREN (Scientific and Technological Bioresource Nucleus), Universidad de La Frontera, Temuco, Chile.
} 

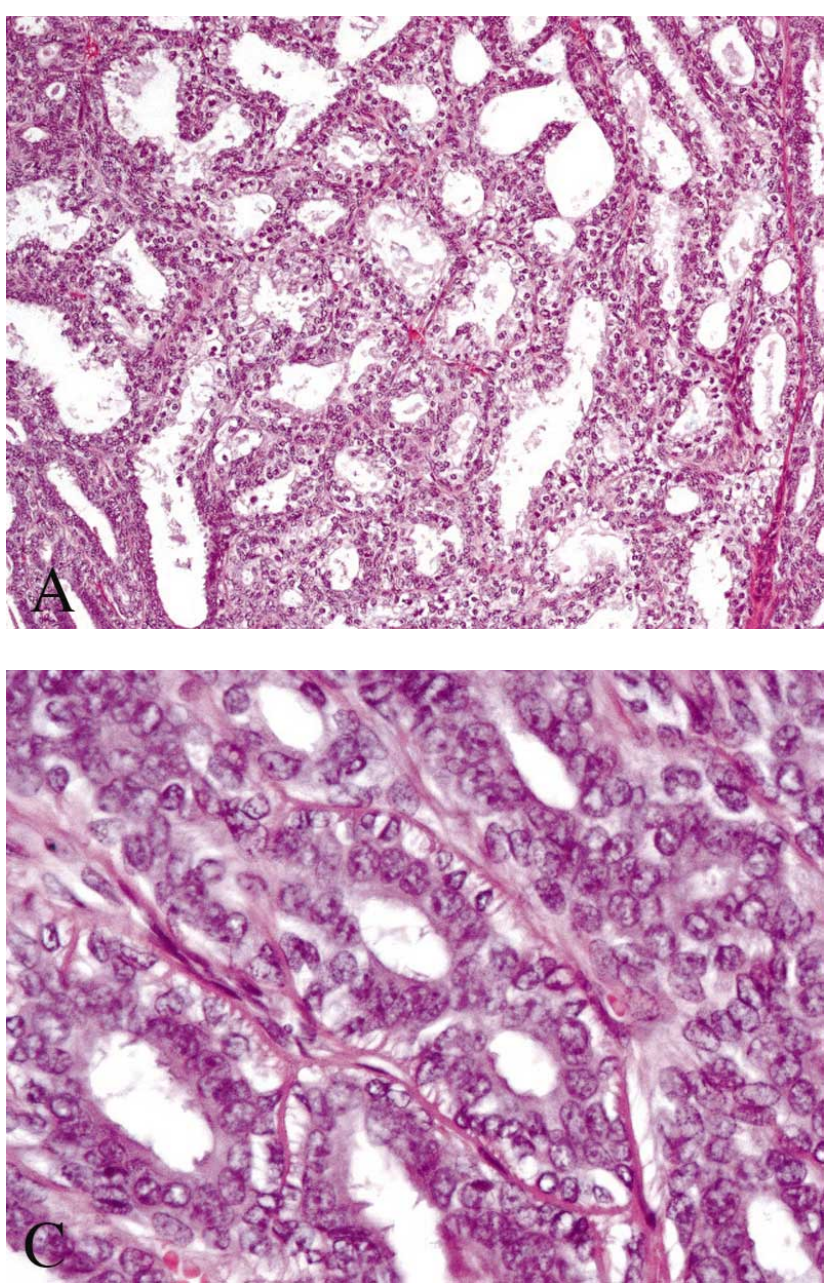

Fig. 1. A-B (HE, 200X), C (HE, 400X). Proliferación neoplásica compuesta por estructuras tubulares conformadas por células epiteliales ductales normotípicas y células mioepiteliales dispuestas basalmente, de citoplasma vacuolado y claro; con presencia de abundantes calcificaciones pequeñas-medianas intraluminales. $\mathrm{D}$, estudio inmunohistoquímico para actina músculo liso (SMA) positivo en células mioepiteliales. E. Imagen $\mathrm{D}$ a mayor aumento.

\section{DISCUSIÓN}

Las neoplasias mamarias derivadas de células mioepiteliales son infrecuentes, siendo agrupadas por Tavassoli en tres entidades: mioepiteliosis, adenomioepitelioma y carcinoma mioepitelial (Tavassoli, 1991).
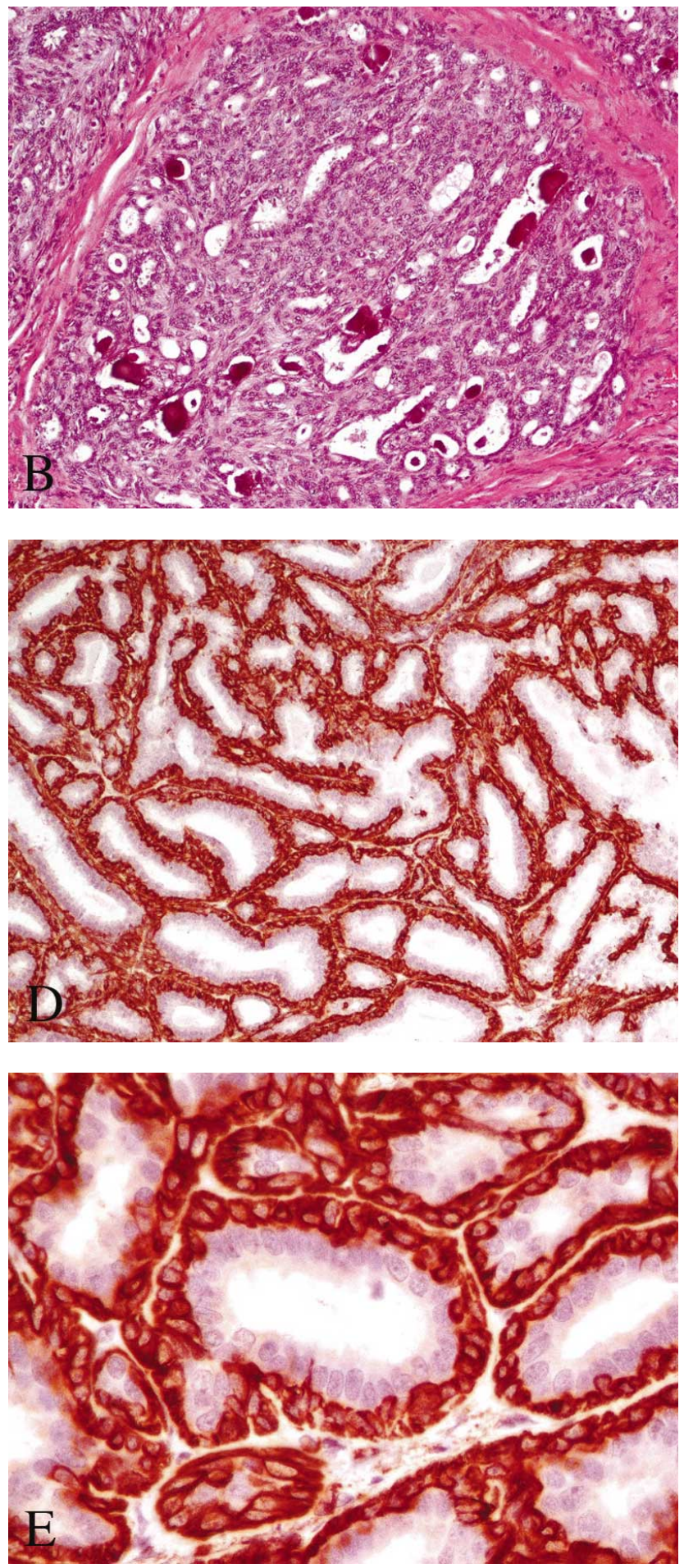

El adenomioepitelioma fue descrito por primera vez en 1970 por Hamperl, correspondiendo a un tumor bifásico, constituído por células epiteliales ductales y mioepiteliales de los lobulillos y conductos mamarios (Chu et al.; Lee et al.; Rosen; Hamperl, 1970). 
La mayoría de estos tumores presentan un comportamiento benigno, sin embargo, excepcionalmente pueden tener un curso maligno; pudiendo recurrir localmente independientemente de su comportamiento biológico (Catena et al.; Foschini \& Eusebi, 1998, Lee et al.; Rosen; Tavassoli).

Esta neoplasia afecta generalmente a mujeres de edad avanzada, con un promedio de 50 años (31 a 72 años). Clínicamente se presentan como una masa palpable indolora, solitaria variando el tamaño entre $0,5-3,4 \mathrm{~cm}$ (promedio: $1,5 \mathrm{~cm}$ ). Los hallazgos en la mamografía son inespecíficos apareciendo generalmente como masas circunscritas, sin calcificaciones intratumorales en su mayoría catalogados como BIRADS 4, mientras que lesiones mal delimitadas con presencia de microcalcificaciones hacen sospechar al radiólogo un comportamiento maligno. En la ecotomografía por su parte se reconoce como un nódulo hipoecoico relativamente bien circunscrito pudiendo presentar refuerzo posterior y en raras ocasiones cambios quísticos (Tavassoli; Catena et al.; Lee et al.; Howlett et al., 2003).

Microscópicamente, este tumor puede presentar un patrón fusado, lobular o tubular, siendo este último el más frecuentemente descrito, estando a su vez conformadas estas estructuras tubulares por células epiteliales ductales de escaso citoplasma y núcleos hipercromáticos, mezcladas con células mioepiteliales de citoplasma vacuolado y claro dispuestas basalmente. El estudio inmunohistoquímico con positividad para actina músculo liso (SMA), p63 y CD10 demuestra la proliferación de células mioepiteliales mientras que citoqueratina 5/6 (CK 5/6) y antígeno carcinoembrionario (CEA) son positivos en el componente epitelial ductal (Chu et al.; Catena et al.; Tavassoli; Hikino et al., 2007; Choi et al., 1996). El caso descrito presentó un patrón tubular, con márgenes bien definidos y positividad para SMA (Figura 1D) en el estudio inmunohistoquímico. Dada su baja frecuencia no hay criterios histológicos bien definidos de malignidad, sin embargo, la literatura menciona como elementos sospechosos de malignidad a la presencia de necrosis, componente de células fusiformes, márgenes tumorales infiltrativos, atipía citológica y recuento mitótico mayor a 5 por 10 campos de aumento mayor (Loose et al., 1992; Catena et al.; Foschini \& Eusebi).

El tratamiento de esta neoplasia dependerá de su comportamiento biológico, siendo la exéresis completa el tratamiento de elección para tumores benignos, pudiendo recurrir en casos de resecciones incompletas como en el presente caso reportado o bien en lesiones multifocales. Por el contrario para lesiones sospechosas de malignidad se recomienda realizar estudio histopatológico intraoperatorio para confirmar la naturaleza de la lesión y realizar de esta manera una resección con criterio oncológico que incluya disección axilar o estudio del linfonodo centinela y posterior estudio de diseminación, reportando la literatura metástasis en cinco casos que presentaron compromiso de nodos linfáticos regional, óseo (costilla, mandíbula y columna lumbar), pulmonar y cerebral (Catena et al.; Foschini \& Eusebi; Chu et al.; Hikino et al.; Loose et al.; Tavassoli; Chen et al., 1994).

En resumen, el adenomiepitelioma es un infrecuente tumor de la mama generalmente de comportamiento biológico benigno, sin embargo, esta neoplasia debe ser considerada dentro de los diagnósticos diferenciales de lesiones tumorales benignas (adenoma tubular, fibroadenoma, adenosis esclerosante) como malignas.

TAPIA, E. O. Adenomyoepithelioma of the breast: A case report. Int. J. Morphol., 29(3):891-894, 2011.

SUMMARY: Breast adenomyoepithelioma is a rare tumor, characterized by the biphasic proliferation of epithelial and myoepithelial cells. We present clinical and morphological features of a case of benign adenomyoepithelioma diagnosed in a 34 year old patient in the Hernán Henríquez Aravena Hospital in Temuco.

KEY WORDS: Breast neoplasm; Adenomyoepithelioma; Myoepithelial cells.

\section{REFERENCIAS BIBLIOGRÁFICAS}

Catena, F.; Santini, D.; Di Saverio, S.; Ansaloni, L. \& Taffurelli, M. Adenomyoepithelioma of the Breast: An Intricate Diagnostic Problem. Breast Care, 3(2):125-7, 2008.

Chen, P. C.; Chen, C. K.; Nicastri, A. D. \& Wait, R. B. Myoepithelial carcinoma of the breast with distant metastasis and accompanied by adenomyoepitheliomas. Histopathology, 24(6):543-8, 1994.
Choi, J. S.; Bae, J. Y. \& Jung, W. H. Adenomyoepithelioma of the breast--its diagnostic problems and histogenesis. Yonsei Med. J., 37(4):284-9, 1996.

Chu, P. Y.; Teng, T. H.; Cheng, T. F. \& Lee, Ch. Adenomyoepithelioma of the Breast. A Case Report. Tzu. Chi. Med. J., 18:65-7, 2006. 
Foschini, M. P. \& Eusebi, V. Carcinomas of the breast showing myoepithelial cell differentiation. A review of the literature. Virchows Arch., 432(4):303-10, 1998.

Hamperl, H. The myothelia (myoepithelial cells). Normal state; regressive changes; hyperplasia; tumors. Curr. Top. Pathol., 53:161-220, 1970.

Hikino, H.; Kodama, K.; Yasui, K.; Ozaki, N.; Nagaoka, S. \& Miura, H. Intracystic adenomyoepithelioma of the breast--case report and review. Breast Cancer, 14(4):42933, 2007.

Howlett, D. C.; Mason, C. H.; Biswas, S.; Sangle, P. D.; Rubin, G. \& Allan, S. M. Adenomyoepithelioma of the breast: spectrum of disease with associated imaging and pathology. AJR Am. J. Roentgenol., 180(3):799-803, 2003.

Lee, J. H.; Kim, S. H.; Kang, B. J.; Lee, A. W. \& Song, B.J. Ultrasonographic features of benign adenomyoepithelioma of the breast. Korean J. Radiol., 11(5):522-7, 2010.

Loose, J. H.; Patchefsky, A. S.; Hollander, I. J.; Lavin, L. S.; Cooper, H. S. \& Katz, S. M. Adenomyoepithelioma of the breast. A spectrum of biologic behavior. Am. J. Surg. Pathol., 16(9):868-76, 1992.

Rosen, P. P. Adenomyoepithelioma of the breast. Hum. Pathol., 18(12):1232-7, 1987.

Tavassoli, F. A. Myoepithelial lesions of the breast. Myoepitheliosis, adenomyoepithelioma, and myoepithelial carcinoma. Am. J. Surg. Pathol., 15(6):554-68, 1991.
Dirección para correspondencia:

Dr. Oscar Tapia E.

Departamento de Anatomía Patológica

Facultad de Medicina

Universidad de La Frontera.

Manuel Montt 112

Código Postal 478-1176

Temuco

CHILE

Fono: $56-45-296530$.

Email: otescalona@gmail.com

Recibido : 08-06-2011

Aceptado: 22-07-2011 